\title{
A participação eletrônica no Uruguai, Chile e Colômbia a partir da teoria da ação comunicativa
}

\author{
Jorge Lheureux de Freitas \\ Pontifícia Universidade Católica do Rio Grande do Sul (PUCRS) \\ Marie Anne Macadar \\ Universidade Federal do Rio de Janeiro (UFRJ)
}

Eder Henriqson

Pontifícia Universidade Católica do Rio Grande do Sul (PUCRS)

Baseado nos depoimentos de representantes de organizações não governamentais, o objetivo desta pesquisa consistiu em estudar e comparar a participação eletrônica no Uruguai, Colômbia e Chile com fundamento na teoria da ação comunicativa (TAC). As evidências mostraram que Chile e Colômbia contam com lei específica que regula o tema e que a Colômbia é a única das três nações com um programa institucional de e-participação. As entrevistas indicaram que a presença da e-participação em todos os países é tímida e que, apesar da percepção de discurso governamental e vontade política favoráveis, os recursos disponíveis, nesse âmbito, estão aquém do necessário. Por final, as contribuições fizeram emergir uma discussão sobre a conveniência do modelo preconizado pela Open Government Partnership (OGP).

Palavras-chave: participação eletrônica, teoria da ação comunicativa, governo aberto, avaliação, Uruguai, Chile, Colômbia

[Artigo recebido em 28 de fevereiro de 2018. Aprovado em 26 de março de 2019.] 


\section{La participación electrónica en Uruguay, Chile y Colombia a partir de la teoría de la} acción comunicativa

Basado en los testimonios de los representantes de organizaciones no gubernamentales, el presente trabajo buscó estudiar y comparar la participación electrónica en Uruguay, Colombia y Chile interpretados a partir de la teoría de la acción comunicativa. Las evidencias mostraron que Chile y Colombia cuentan con ley específica que regula el tema y que Colombia es la única de las tres naciones con un programa institucional de e-participación. Las entrevistas indicaron que en todos los países es débil la presencia de la e-participación y que, a pesar de la percepción de un discurso gubernamental y de una voluntad política favorables, los recursos disponibles están por debajo de lo necesario. Por último, las contribuciones hicieron emerger una discusión sobre la conveniencia del modelo preconizado por la Open Government Partnership, OGP.

Palabras clave: participación electrónica, teoría de la acción comunicativa, gobierno abierto, evaluación, Uruguay, Chile, Colombia

\section{Eletronic participationin Uruguay, Chile and Colombia from the communicative action theory}

This study aims to study and compare electronic participation in Uruguay, Colombia and Chile through the testimonies of the members of non-governmental organizations, interpreted by the theory of communicative action. The evidence showed that Chile and Colombia have a specific law that regulates the subject and that Colombia is the only one of the three nations with an institutional e-participation program. According to the interviews, e-participation is weak in all the countries and, despite the perception of a favorable governmental discourse and political will, the available resources are below what is required. Finally, the contributions gave rise to a discussion about the appropriateness of the model advocated by the Open Government Partnership, OGP.

Keywords: electronic participation, communicative action theory, open government, evaluation, Uruguay, Chile, Colombia 


\section{Introdução}

Desde os idos tempos, a história da humanidade transcorre pelas rotas do poder, que pode ser considerado como a capacidade de "um ator influir de forma assimétrica nas decisões de outros atores sociais, de modo que favoreçam a vontade, os interesses e os valores do ator que tem o poder (CASTELLS, 2009, p. 33)". Por séculos, o poder estatal se manteve absoluto pela força, pelos interesses econômicos, religiosos e pelos grupos que se acercaram, constituindo a classe dominante.

A reação ao status quo veio por meio deflagrações como, por exemplo, a independência americana e a revolução francesa, que introduziram novas abordagens dos conceitos de estado, democracia e direitos do cidadão (OLIVEIRA, 2007), embora Marx e Engels (1999) classificassem o último movimento como um deslocamento de poder feudal para a burguesia, uma troca de comando entre as minorias da casta dominante.

A partir da segunda metade do século 20 , com a propagação de diversas formas de comunicação, maior conscientização dos direitos civis, movimentos sociais etc., a ideia de participação cidadã se fortalece como meio de empoderamento. Nesse sentido, Arnstein (1969), observa que "participação cidadã é um pouco como comer espinafre: ninguém é contra, em princípio, porque é bom para você ( $p$. 216)", mas adverte, adentrando no ponto crítico da questão, que participação sem redistribuição de poder, além de ser um processo vazio para os sem poder, legitima falsamente o status quo dos dominadores.

Em conformidade com a visão de Arnstein, este trabalho busca estudar a participação, com prevalência da participação eletrônica, a e-participação, como fenômeno de transformação social. Para tanto, a teria da ação comunicativa, TAC (HABERMAS, 1981, vol. 1 e 2; 1984), forjada a partir do estudo crítico da ação social comunicativa, constitui a lente teórica por excelência para estudar o fenômeno. 0 lócus da pesquisa compreende três nações: Uruguai, nação de pequena extensão territorial, homogênea geograficamente, com poucas diferenças regionais, politicamente estável e com índice de desenvolvimento humano, IDH, muito bom em termos continentais; Colômbia, país de contrastes, com fortes diferenças geográficas (Andes, Pacífico, Caribe e Amazônia), populacionais e de renda per capta, com IDH baixo comparado aos índice das demais nações da América do Sul e que conta com movimentos guerrilheiros em processo de pacificação; e Chile, uma nação com fortíssimos contrastes geográficos, populações e etnias distintas e melhor IDH das nações estudadas.

Por final, o segmento escolhido para ser ouvido recaiu sobre os representantes de organizações não governamentais que participam, de uma forma ou de outra, do 
processo de governo aberto em suas nações, público potencialmente conhecedor do universo a ser estudado. Dessa conjunção de fatores, o presente estudo objetiva estudar e comparar os programas de participação no Uruguai, Chile e Colômbia, a partir da perspectiva dos representantes das organizações não governamentais e com base na TAC.

\section{Teoria da ação comunicativa}

Jürgen Habermas, filósofo e sociólogo alemão da segunda geração da escola de Frankfurt, movimento responsável pela criação da teoria crítica, desenvolveu a teoria da ação comunicativa, TAC (HABERMAS, 1981, vol. 1 e 2; 1984), que vislumbra a comunicação como núcleo da ação social. Essa fala, de acordo com a construção teórica, realiza-se por meio de uma ação intersubjetiva, ou seja, entre sujeitos capazes de falar e entender, e deve se estabelecer em condições de simetria e de igualdade entre as partes, sem qualquer forma de coação, dominação ou submissão. Essa simetria, portanto, criaria condições para uma comunicação resultante de um entendimento entre as partes, construído mediante a argumentação e busca do consenso, sem qualquer imposição de um dos falantes.

A partir dessas premissas, pode-se resumir o núcleo da TAC pelas quatro pretensões de validade, ação comunicativa e ação estratégica, como segue:

\section{Quadro 1 - Núcleo da teoria da ação comunicativa}

\begin{tabular}{|c|c|c|c|}
\hline \multirow[t]{5}{*}{$\begin{array}{l}\text { Pretensão } \\
\text { de validade }\end{array}$} & Tipo & Mundo & Contexto \\
\hline & Verdade & Objetivo & O enunciado da fala deve ser verdadeiro \\
\hline & Legitimidade & Normativo & $\begin{array}{l}\text { Fala compatível com o contexto normativo } \\
\text { vigente em termos de valores sociais, morais e } \\
\text { históricos daquele momento e local }\end{array}$ \\
\hline & $\begin{array}{l}\text { Sinceridade ou } \\
\text { intencionalidade }\end{array}$ & Subjetivo & $\begin{array}{l}\text { A intenção expressa do falante corresponde ao } \\
\text { que ele pensa }\end{array}$ \\
\hline & \multicolumn{2}{|c|}{ Compreensibilidade } & $\begin{array}{l}\text { O conteúdo da comunicação deve ser } \\
\text { compreensível para todos os agentes da fala }\end{array}$ \\
\hline \multicolumn{3}{|c|}{ Ação comunicativa } & $\begin{array}{l}\text { A fala se estabelece em condições de simetria } \\
\text { entre as partes, buscando o entendimento, } \\
\text { dentro de uma comunicação inteligível } \\
\text { para todos, verdadeira, sincera e legítima. } \\
\text { É indispensável a presença de TODAS as } \\
\text { pretensões de validade }\end{array}$ \\
\hline
\end{tabular}




\begin{tabular}{|l|l|}
\hline Ação estratégica. & $\begin{array}{l}\text { Ocorre quando UMA OU MAIS das pretensões de } \\
\text { validade são violadas na comunicação e quando } \\
\text { a ação de, pelo menos, um dos atores, se vale } \\
\text { de cálculos egocêntricos de proveito próprio, } \\
\text { dissimulação etc. }\end{array}$ \\
\hline Comunicação sistematicamente distorcida & $\begin{array}{l}\text { Quando o conteúdo de uma fala considerada } \\
\text { ação estratégica é repetido de tal forma que } \\
\text { se torna ação comunicativa na aparência, e os } \\
\text { agentes da fala a reiteram, sem se dar conta de } \\
\text { sua essência estratégica, de dissimulação. }\end{array}$ \\
\hline
\end{tabular}

Fonte: adaptado de Habermas $(1981,1984)$.

\section{Governo aberto}

A crescente influência da tecnologia na rotina do cidadão e da gestão pública, conjugada com a rapidez das mudanças sociais e demográficas, propiciou que iniciativas governamentais, focadas em aproximar Estado e cidadão, fossem organicamente estruturadas em um conceito novo de administração estatal, o chamado governo aberto (VELJKović; Bogdanović-Dinić; STOIMENOV, 2014).

Nesse caminho, a Austrália estabeleceu, em 2009, os fundamentos de seu governo aberto baseados em informação, engajamento e participação por meio do relatório Engage: getting on with government 2.0 (GRUEN, 2009); o Reino Unido apresentou ao parlamento o plano de ação voltado para o fortalecimento do papel do cidadão e da sociedade civil (TREASURY, 2009) e os Estados Unidos estabeleceram que essa nova expressão de administração pública se fundaria na tríade participação, transparência e colaboração (HARRISON et al., 2012).

$\mathrm{Na}$ estrutura de governo aberto americana, a transparência - amplo acesso aos dados e informações governamentais de forma a propiciar um crescente monitoramento e controle dos cidadãos - e a participação - oportunidade da cidadania influenciar ativamente no processo de governança, elaboração das políticas públicas e tomada de decisão (ATTARD et al., 2015) -, constituem os pilares mais conhecidos do tripé de sustentação dessa modalidade de governo. A colaboração, terceiro fundamento, ultrapassa a participação, eis que resulta no compartilhamento do conhecimento e habilidades dos stakeholders com o Estado, gerando novo conhecimento com potencial de criar melhores soluções (HANSSON; BELKACEM; EKENBERG, 2015).

Outro grande marco de governo aberto foi a criação do organismo internacional Parceira de Governo Aberto ou Open Government Partnership, OGP, em 2011. Atualmente composto por mais de 60 nações, o ingresso do país na OGP demanda que a nação se comprometa com a promoção da transparência, accountability, 
empoderamento da cidadania e uso de tecnologia para melhorar a governança (ATTARD et al., 2015), por meio de um modelo baseado na elaboração e execução de planos de ação bienais fundados em práticas voltadas para a temática adotada pelo organismo (HARRISON; PARDO; COOK, 2012). Em essência, o significado de governo aberto não está "tanto na tecnologia, mas na interoperabilidade, abertura e melhoria da dimensão participativa que a tecnologia pode permitir, como também na mudança fundamental dos governos operarem (HANSSON; BELKACEM; EKENBERG, p. 4, 2015)".

Nesse contexto, Meijer et al. (2012) defendem que abertura em governo se materializa pela transparência, que os autores qualificam como "visão", e pela participação, a "voz", que podem se sobrepor, dentro de uma relação sinérgica, em que a primeira "garante que o público tenha acesso à informação sobre o governo e a outra provê o acesso do público a esse mesmo governo (p. 14)." Adotando os conceitos de voz e visão, estudo sobre a cultura organizacional nas organizações públicas defende que o ambiente interno ideal para o desenvolvimento da cultura de governo aberto ocorre quando a "visão" propicia o compartilhamento e o ganho de conhecimento além dos limites funcionais, a "voz" viabiliza a livre manifestação dos pontos de vista e a rede possibilita uma atuação interdepartamental (RUIJER, et al., 2016). Na medida em que a participação é a voz, importante examinar o tipo de comunicação que essa voz estabelece entre cidadão e estado, se é comunicativa, voltada para o entendimento, verdade, legitimidade e compreensibilidade ou se insere como ação estratégica, fundada na dissimilação.

A mudança demandada pela implantação dos fundamentos de governo aberto enfrenta uma série de dificuldades, como a falta de recursos, estruturas burocráticas sem flexibilidade, rígido controle político, infraestrutura deficitária, barreiras legais, inexistência de um planejamento eficaz, falta de conhecimento sobre o tema e resistência (SANDOVAL-ALMAZAN; GIL-GARCIA, 2016). Cabe, nesse plano, questionar a vontade política dos governos (pretensão da intencionalidade), se a implantação do governo aberto decorre de real desejo de mudança ou mera retórica de um discurso considerado ação estratégica. Por final, a falta de compreensão da questão e a cultura arraigada de segredo das informações e das ações do estado poderiam, da mesma forma, explicar a postura de resistência de segmentos dos servidores públicos (DAVIES; BAWA, 2012).

No âmbito externo às organizações públicas, as mídias sociais representam um canal estratégico na promoção do governo aberto, em que Twitter, Facebook, blogs e plataformas wiki viabilizam a criação de conteúdo, troca de ideias, compartilhamentos e utilização das informações públicas (SANDOVAL-ALMAZAN; GIL GARCIA, 2016). No entanto, em que pese serem as mídias sociais ferramentas de uso livre, sem encargos diretos, as organizações não podem descurar a 
necessidade de investimentos consideráveis em termos de recursos humanos, treinamento, infraestrutura tecnológica, tempo de resposta, monitoramento e manutenção (LEE; KWAK, 2012).

\section{Participação eletrônica}

A e-participação representa o processo que agrega as ferramentas de tecnologia da informação e comunicação, TIC, à consulta e que intervém e virtualiza o procedimento, objetivando viabilizar o envolvimento do cidadão e potencializar seu papel na deliberação e tomada de decisão (Sæbø; ROSE; FLAK, 2008), influenciando, num plano macro, a construção das políticas públicas e as questões de governança em geral, bem como propiciando opinar sobre questões mais pontuais, como serviços eletrônicos oferecidos pelo Estado (SUSHA; GRÖNLUND, 2012).

O sucesso de iniciativas de e-participação guarda estreita relação com a percepção de valor do cidadão. Esse ganho se materializaria por ações que garantam transparência, pronta capacidade de resposta, feedback e prestação de contas do governo, que melhorem a qualidade e eficiência, que considerem a conveniência do usuário, que se preocupem com a clareza e o entendimento das mensagens, que busquem a maior pluralidade de contribuições possíveis e que se voltem efetivamente para o bem-estar e a satisfação do cidadão (PANOPOULOU; TAMBOURIS; TARABANIS, 2014). Revisão da literatura sobre e-participação (MEDAGLIA, 2012) detectou que o foco de interesse da academia se deslocou dos governos para o cidadão e demais stakeholders, demonstrando a importância da geração de valor, bem como ultrapassou os limites da tecnologia, atingindo uma ampla gama de fatores contextuais.

No âmbito da implementação de uma iniciativa de e-participação, o contexto, segundo Susha e Grönlund (2014), pode atuar como elemento de restrição ou de incentivo a partir de três níveis: 1 . Clima político - em função da clareza ou ambiguidade da proposta democrática do instrumento de consulta ou em decorrência da identidade ou diferença de posições e expectativas dos gestores em relação à postura dos representantes da sociedade civil. Nesse nível, as pretensões de validade da TAC - verdade, legitimidade, intencionalidade e compreensibilidade - adquirem especial relevância no entendimento do estudo. 2. Demandas tecnológicas - em virtude dos altos custos de investimento, da necessidade de expertise do corpo funcional e dos cuidados relativos à miríade de procedimentos de certificação e validação. 3. Implementação da gestão- como consequência de deficiências no desenho organizacional, nas práticas de gestão e recursos financeiros e humanos. 
Abordagem interessante sobre a e-participação diz respeito a seu alcance potencial e evolução, pois, de acordo com a avaliação de pesquisadores e executivos de agências públicas (EvANS; CAMPOS, 2013), não está claro se os significativos esforços e investimentos em recursos financeiros e humanos resultaram em um incremento efetivo na participação cidadã. Por outro lado, quando ocorre o efetivo incremento da participação, esse engajamento pode, em termos potenciais, permitir que grupos mais organizados, com mais recursos e expertise de mobilização, não raro resguardando interesses econômicos de segmentos específicos, defendam suas posições com mais vigor e efetividade, sobrepondo-se a outros, com menor força e poder de comunicação, embora com bandeiras voltadas aos interesses sociais mais abrangentes (SCHULZ; NEWIG, 2015).

Dentro da perspectiva do que a TAC consideraria como assimetria da comunicação, a e-participação pode propiciar debates desequilibrados das distintas visões e perspectivas, demandando, para recompor a harmonia da discussão, estender a consulta a outros ambientes, como fóruns com a sociedade civil e debates na esfera política, por exemplo (SPILIOTOPOULOU et al., 2014).

No que poderia ser considerada uma postura não ortodoxa, países autoritários como Bahrein, Cazaquistão e Malásia apresentaram níveis de e-participação superiores, respectivamente, aos da França, Suécia e Alemanha, o que seria uma tentativa de legitimar os regimes da primeira tríade de nações mencionadas, "travestindo-as" de democracias, principalmente para um mercado global cada vez mais refratário a ditaduras (ÅstRöM et al., 2012). Tratam-se, pois, de infrações às pretensões da validade da verdade e da intencionalidade da TAC.

Outro caso de infração à TAC, cuja principal turbação ocorre no plano da pretensão da legitimidade, eis que de forma subliminar e ilegítima tolhe um direito do cidadão, pode ser visto no estudo sobre Uganda. Nessa nação com forte histórico político de autoritarismo e golpes, o cidadão daquele país busca, preferencialmente, o engajamento online com outros cidadãos e não com o Estado, visto sua percepção de baixa efetividade de resposta governamental e medo de eventual perseguição governamental como represália ao conteúdo da postagem (WAKABI; GRÖNLUND, 2015).

Em função da possibilidade da e-participação atuar em todas as fases do processo da gestão pública, os defensores da corrente legalista enfatizam que detentores de mandato popular e administradores públicos representam o segmento legal e constitucionalmente competente para atuar na fase de tomada de decisão e na execução das políticas, e questionam a legitimidade da atuação dos processos participativos nessas fases, retirando competências expressamente definidas pela carta maior da nação e arcabouço legal em geral (VAN DJICK, 2012). 
Por outro lado, focada em mídias sociais como ferramenta de e-participação, Mergel (2013) relativiza esse argumento da intervenção indevida, destacando que as mídias sociais não atuam como substitutos de serviços governamentais, virtuais ou não, mas complementarmente, objetivando alcançar, por meio de uma interação em dois sentidos, o cidadão que não se vale dos tradicionais meios de interação com o governo. No campo de e-participação, as mídias sociais representariam ferramentas que poderiam, em tese, substituir as reuniões presenciais, debates e outras formas tradicionais de envolvimento cívico (ZAVATTARO; SEMENTELLI, 2014).

No terreno das mídias sociais, Picazo-Vela, Gutiérres-Martínez e Luna-Reyes (2012) apontam que a implementação dessas ferramentas demanda cuidados e estratégias específicas, como atenção ao contexto, permanente monitoramento das informações e comentários e conhecimento do problema para ter condições. Além das estratégias referidas, os gestores das organizações devem lidar com as barreiras à expansão das mídias sociais, tais como o nível de conectividade, habilidade dos usuários no uso das mídias, qualidade e confiabilidade da informação, relevância e pertinência dos conteúdos, prazo de utilidade da informação, questões de segurança e a radicalização dos debates (DINI; WAHID; Sæbø, 2016).

Por final, a própria organização pública pode representar outro obstáculo, visto que se insere em cenário fortemente regulado, burocrático e, não raro, avesso a mudanças, em que a introdução das mídias sociais representa um elemento de turbação, de incerteza e pouco controle, pois desenvolvimento e atualização das plataformas compete a terceiros, com influência zero do Estado nas modificações tecnológicas, sem contar o volátil comportamento do usuário (MERGEL, 2013).

Importante referir que a e-participação representa um inegável recurso de democratização do Estado, mas seus resultados, como apontam as referências apresentadas neste capítulo, vão depender das estratégias estabelecidas, dos recursos disponíveis, da correção dos procedimentos preparatórios, do desenho, amigabilidade e facilidade de uso da ferramenta a ser utilizada, da compreensibilidade dos conteúdos das mensagens, da consulta disponibilizada à sociedade e, principalmente, da intenção (pretensão da intencionalidade) dos promotores do processo de e-participação.

\section{Procedimentos metodológicos}

O presente estudo, inserido no campo da administração da informação e que trata da e-participação no Uruguai, Chile e Colômbia, constitui um estudo de casos múltiplos, opção de investigação compatível com o positivismo, interpretativismo e postura crítica e que se adéqua às diversas crenças e opções epistemológicas do autor (MYERS, 1997). 
De forma a situar a linha de condução do presente estudo, importante referir as escolhas adotadas, a saber:

- Abordagem qualitativa e indutiva, que busca novos conceitos e contribuições teóricas para o campo, capturando concepções e relacionamentos não aparentes para os informantes (GIOIA; CORLEY ; HAMILTON, 2013).

- Inserção na linha crítica, adotando como lente teórica a teoria da ação comunicativa.

- Adoção complementar do interpretativismo.

Essa proximidade com o interpretativismo vem ao encontro da posição "crítica interpretativista" de Doolin e MacLeod (2005) e do posicionamento de CecezKecmanivic (2005), que defende que os trabalhos acadêmicos críticos admitem vários tipos de propostas, dentre elas a análise crítica do discurso, opção deste estudo, que parte do contexto amalgamado por desigualdades sociais, diferenças econômicas e culturais para então entender a linguagem (PEDRO, 1998).

De forma a manter a coerência da proposta, o instrumento adotado para a coleta foi o de entrevistas abertas, conduzidas tendo em vista pontos fundamentais previamente determinados, tais como transparência, e-participação, dados abertos, verdade, intencionalidade, legitimidade, compreensibilidade, assimetria, resultados, sistemas de informação, de forma a garantir convergência, ainda que parcial, entre os depoimentos resultantes das entrevistas realizadas. As entrevistas pessoais foram realizadas nos municípios de Montevideo, Bogotá, Medellin, Santiago do Chile e Antofagasta. No total foram 14 entrevistados, de 14 organizações não governamentais, todas elas atuando diretamente no âmbito de governo aberto ou em áreas afins. A distribuição das entrevistas ocorreu da seguinte forma:

\section{Quadro 2 - Distribuição das entrevistas}

\begin{tabular}{|l|c|l|l|}
\hline País & Entrevistados & Período & Forma de entrevista \\
\hline Uruguai & 4 & março a maio de 2016 & 03 in loco e 01 por skype \\
\hline Colômbia & 5 & agosto de 2016 & 03 in loco e 2 por skype \\
\hline Chile & 5 & maio de 2017 & 05 in loco \\
\hline
\end{tabular}

Fonte: elaboração própria.

Pesquisas em portais oficiais e junto aos seguidores do Twitter e Facebook desses sites, em eventos de governo aberto e snowball, foram os procedimentos adotados para identificar potenciais entrevistados. As entrevistas foram traduzidas e transcritas pelos autores e a codificação dos depoimentos ocorreu via software Maqxda, versão 11, resultando num total de 18 códigos primários. 
A análise dos dados seguiu as orientações da análise crítica do discurso, ACD, que, conforme Pedro (1988), atém-se à linguagem com expressão de um contexto fundado em desigualdades sociais, econômicas e culturais e seguiu o "método tridimensional de análise do discurso", de Fairclough (1998). A partir da seleção dos textos dos discursos, marcados e ordenados por meio do Maqxda, a ACD foi realizada em três etapas:

- Descrição - análise detalhada do texto;

- Interpretação - pela interpretação, busca entender a prática discursiva do texto; e

- Explicação - conecta as interpretações ao ambiente social, econômico e cultural.

De forma a melhor explicar o processo de análise dos dados coletados, o Quadro a seguir apresenta trecho do texto de uma entrevista realizada, acompanhada da respectiva descrição do texto, interpretação e explicação, de acordo com o modelo tridimensional de análise:

\section{Quadro 3 - Exemplo do processo de análise proposto}

\begin{tabular}{|c|c|c|c|}
\hline Texto & Descrição & Interpretação & Explicação \\
\hline $\begin{array}{l}\text { "pode } \\
\text { ser que } \\
\text { participem } \\
10,11 \\
\text { organizações, } \\
\text { nada mais" }\end{array}$ & $\begin{array}{l}\text { Cerca de } 10 \\
\text { organizações } \\
\text { da sociedade } \\
\text { civil participam } \\
\text { das decisões } \\
\text { de governo } \\
\text { aberto. }\end{array}$ & $\begin{array}{l}\text { Representa a } \\
\text { participação da } \\
\text { sociedade civil } \\
\text { na elaboração } \\
\text { das políticas de } \\
\text { governo aberto. }\end{array}$ & $\begin{array}{l}\text { Existem milhares de } \\
\text { organizações da sociedade } \\
\text { civil. Qual o porquê } \\
\text { dessas } 10 \text { ? Tentativa de } \\
\text { legitimação da pauta } \\
\text { governamental por meio } \\
\text { de colegiado controlável? }\end{array}$ \\
\hline
\end{tabular}

Fonte: elaboração própria.

\section{Estudando as percepções dos entrevistados}

A exemplo da linha adotada no planejamento deste estudo e na coleta de dados da pesquisa de campo, a análise dos conteúdos das entrevistas realizadas seguiu idêntica orientação, entendendo a participação como uma "fala", uma comunicação entre o estado e o cidadão, criticável sob os fundamentos da ação comunicativa, ou seja, por meio das pretensões da compreensibilidade, sinceridade, legitimidade e verdade. Nestes termos, importante registrar que se trata de uma aplicação mais ampla dos fundamentos da TAC, que poderia ser considerada como não ortodoxa. Dentro dessa perspectiva, os depoimentos iniciais indicaram que o estabelecimento da comunicação no meio virtual depende da presença de dois requisitos adicionais: acessibilidade, ou acesso à internet, e amigabilidade, que significa a facilidade de 
navegar entre as páginas web, possibilitando ao usuário alcançar com tranquilidade, de forma intuitiva, os pontos e informações que permitam a interação.

\section{Entrevistas no Uruguai}

A pesquisa de campo no Uruguai envolveu entrevistas com quatro depoentes de distintas organizações não governamentais: UR1, egresso de organização da sociedade civil que atua como intermediador entre essas entidades e o governo; UR2, integrante de organização voltada para a informação; UR3, membro de entidade vinculada aos direitos do cidadão; e UR4, ocupante de cargo em ONG cujo foco de atuação é a informação.

Questionado sobre a conectividade no país, UR4 explicou que praticamente toda a população uruguaia é atendida por meio de redes de fibra ótica e há programas de inclusão digital, como o plano Ceibal, que doou notebooks customizados a todos os estudantes. O depoente acrescentou que está sendo organizado outro programa semelhante, mas focado em pessoas da melhor idade. Essas iniciativas resultam de política oficial de disponibilização de acesso, equipamento e desenvolvimento de habilidades da população no uso da internet.

No campo da navegação, UR4 observa que as interfaces da e-participação, a exemplo do que ocorre nos sites de governo aberto em geral, não são amigáveis, não são fluidas e não são compreensíveis, mormente para as faixas menos favorecidas da população. Estudando a questão a partir dos fundamentos da TAC, presentes estão os indicativos de assimetria do processo (não está "ao alcance das pessoas mais humildes'), bem como a ausência de outro requisito básico da ação comunicativa, a compreensibilidade.

Como mencionado, os países membros da OGP devem elaborar planos de ação focados no desenvolvimento do governo aberto, ou seja, e-participação, transparência, accountability e governança eletrônica. No ano de 2014, a Agesic, agência estatal uruguaia encarregada de governo eletrônico e governo aberto, promoveu, durante dois meses, consultas online buscando contribuições para a elaboração do plano de ação de governo preconizado pela OGP. O resultado foram 34 manifestações, sendo 20 delas contendo dúvidas, 10 expressando concordância com o postado e apenas quatro sugestões.

Indagado sobre o posicionamento de dirigente da Agesic, que defende que o povo abre mão da opção online de participação pela sua familiaridade com os debates presenciais, eis que espraiados por todo o país, UR3 discorda, pois entende que a difusão da tecnologia permitiria uma maior participação, ressaltando que a e-participação tende a ampliar seu papel quando "é mostrado para as pessoas 
que é importante, que a opinião das pessoas é importante." Tratar-se-ia de um caso de comunicação sistematicamente distorcido pela repetição da fala sobre a existência de vários espaços presenciais de participação, fato que prejudicaria a e-participação, quando na verdade os motivos seriam outros. Indagado sobre o motivo de não usar o meio eletrônico, o entrevistado responde que "pode haver algum temor da resposta, que as pessoas se deem conta de determinadas coisas".

Sobre o episódio de consulta malsucedida, acerca do plano de ação da OGP, cuja participação mostrou-se irrisória, UR1 afirma que "os mecanismos de inclusão que se utilizaram neste governo na primeira consulta dos planos tiveram um alcance muito limitado e o esforço para corrigir não foi contínuo." UR2, embora reconhecendo a inexpressividade da participação no portal do governo, relativiza a questão da escassez da participação, ao afirmar que os temas consultados não guardam proximidade com o dia a dia do cidadão e da sua realidade.

A partir do insucesso da e-participação na elaboração do plano de ação de governo aberto1, o processo passou a ocorrer exclusivamente via "mesas de diálogo", colegiado com representantes de vários organismos governamentais e representantes da sociedade civil, embora ausente a classe política, conforme observa UR4. Por outro lado, UR3 discute a legitimidade desse colegiado, pois observa que há 3.000 organizações registradas com personalidade jurídica própria, quando nesses colegiados "pode ser que participem 10, 11 organizações, nada mais". O entrevistado vai além da questão da legitimidade (pretensão de legitimidade da TAC), adentrando na pretensão de validade da intencionalidade, ao questionar se os representantes das organizações sociais estariam "abaixando a cabeça a tudo que diz o governo, a tudo que ele propõe".

A partir dessa declaração, restaria a questão do porquê dessa composição das mesas e da possibilidade do governo manejar as reuniões para alcançar e legitimar seus objetivos. Entendendo que o problema não está na composição do colegiado, UR2 observa que a questão é a falta de norma que regule a participação e a composição, pois não há dispositivo legal definindo a quem cabe a representação e acrescenta que, diante dessa lacuna, o estado indica diretamente o representante escolhido. Embora reconhecendo as deficiências das "mesas de diálogo", em que importantes áreas do governo estão ausentes e apresenta-se o absoluto desinteresse da classe política, UR4 mostra otimismo em relação ao quadro, ao destacar que cada reunião das "mesas" tem sido melhor e mais proveitosa que a anterior.

Por sua vez, UR3 pondera que a aprovação de uma lei regulando o tema demanda "vontade política firme, no âmbito político, e disposição de gerar esta abertura

${ }^{1}$ Dentro das obrigações dos países que assinam a declaração de governo aberto da OGP está a participação das organizações da sociedade civil na elaboração e monitoramento dos planos de ação. 
e, portanto, gerar a norma". O depoente destaca a necessidade de aprovação de diploma legal que dote os organismos de participação com os recursos materiais e financeiros para o desenvolvimento dos trabalhos, o que não há. Passando ao largo da questão de edição de dispositivo legal, UR1 foca na disponibilização dos recursos financeiros, visto que há uma multiplicidade de âmbitos onde o engajamento popular pode se expressar, desde que haja aporte de numerário, equipe técnica, infraestrutura, pessoal etc.

Retomando à questão da vontade política, ou falta dela, UR3 relata sobre uma reunião das "mesas de diálogo", em que deveriam comparecer representantes de 10 organismos oficiais, ou seja, servidores de organizações do ente jurídico, poder público, que criou o colegiado que os convocara, e somente três agentes públicos se fizeram presentes. Por final, o entrevistado justificou sua saída das "mesas de diálogo" porque "me dei conta que não havia uma vontade de fundo".

Não somente a elaboração dos planos de ação, a e-consulta e os sistemas de "mesas cidadãs", mas principalmente o modelo preconizado pela OGP demandam uma reflexão maior. Nesse âmbito, UR4 questionou essa adesão ao "pacote" OGP, obrigando os países membros a realizarem planos de ação bienais e adotarem outras providências. Segundo o entrevistado, o Uruguai, como outros países da América do Sul, sancionou uma série de regulamentos, normativas e atos de forma a cumprir com as exigências de organizações internacionais, por meio de documentos que ele chama de "bonitos", mas que não "se implementam e que, inclusive, não respondem a questões internas." $E$ conclui: "Cumpre-se, mas não se cumpre."

\section{Entrevistas na Colômbia}

O rol de entrevistados na Colômbia inclui quatro depoentes, a saber: COL1, membro de ONG que lida com população de baixa renda, muitas delas em localidades remotas, voltada para o empoderamento desse segmento de colombianos; COL2, psicóloga de ONG do interior do país e que apoia a população socialmente vulnerável e vítimas de conflito ${ }^{2}$; COL3, dirigente de ONG que atua junto aos partidos políticos e; COL 4, integrante de organização vinculada à informação.

A Colômbia, por sua configuração geográfica e parcial inserção na selva amazônica, conta com sérios desafios em termos de conectividade. Nesse âmbito, embora destacando os ganhos, "saltos" do governo em termos de tecnologia, COL2 lamenta que as pessoas das camadas mais carentes da população não tenham sido alcançadas por essa evolução, quer por falta de equipamentos ou pela ausência de cobertura da internet e conclui que "nesse ponto, temos um programa um pouco excludente."

\footnotetext{
${ }^{2}$ Pessoas que passaram à condição de vulnerabilidade social em decorrência da atuação da guerrilha.
} 
Sobre a facilidade de navegação, ou amigabilidade, COL3 afirma que nos sites de relacionamento dos partidos políticos, a exemplo do que ocorre nos governamentais, normalmente o usuário "está a muitos clics de distância" daquilo que busca. Na mesma linha, COL2 observa que, embora o grande avanço da plataforma do "Gobierno em línea" ${ }^{3}$, que ajudou muito, "não é amigável, não tem um manejo fácil". Numa análise ampla da situação, a entrevistada avalia que a "Colômbia, em termos de conectividade e de amigabilidade, está anos atrasada em relação a outros países."

A pretensão de validade da compreensibilidade, fundamento para que se estabeleça a comunicação segundo a TAC, recebeu diagnósticos com reservas por parte dos depoentes. COL1 entende que os conteúdos postados não são claros, simples, fáceis de apreender; COL4, por sua vez, destaca desta o tipo de linguagem utilizada, predominantemente técnica, que dificulta a compreensão do cidadão comum e COL3, por final, realça a dificuldade de digerir os conteúdos postados e de entender volumes excessivos de informação. A falta de compreensibilidade, um obstáculo intransponível para o estabelecimento da ação comunicativa de Habermas, impede, da mesma forma, que o cidadão se comunique com o Estado por meio dos processos participativos.

Apesar dos problemas de conectividade na Colômbia, COL1 relata que na fase de preparação dos planos de ação da OGP foi possível viabilizar a participação virtual de um contingente entre 200 a 300 pessoas, residentes em recantos remotos da nação, por meio de ferramentas de TIC desenvolvidas internamente, processo que permitiu que indagassem e opinassem sobre várias matérias, inclusive sobre o plano de ação de governo aberto do país, num processo de "empoderamento da sociedade civil" e que poderia consubstanciar uma tentativa de estabelecer uma ação comunicativa.

"Urna de cristal" é o programa oficial colombiano de e-participação, descrito no site como "a principal plataforma do governo colombiano para a participação cidadã e transparência governamental" que objetiva "transformar a relação entre os cidadãos e o Estado colombiano." Trata-se de uma iniciativa multimídia focada na e-participação com os seguintes canais de relacionamento: rádio, televisão, callcenter, SMS, USSD, Twitter, Facebook, site e newsletter. Sobre a ferramenta, COL2 qualifica o programa como "uma ferramenta que permite fazer sondagens", mas que não possibilita o estabelecimento de um diálogo mais produtivo. COL4, por

\footnotetext{
${ }^{3}$ Conforme o site do programa, a estratégia do "Gobierno en Línea, liderado pelo Ministério da Tecnologia da Informação e Comunicação, é o conjunto de instrumentos técnicos, normativos e de políticas públicas que promovem a construção de um estado mais eficiente, transparente e participativo."
} 
sua vez, discute se as propostas são levadas em conta e recorda que por duas vezes postou expressivo número de questões relevantes e "não apareceu nunca" e conclui que "parece que é um pouco de fachada de participação". Diante da declaração do depoente, caberia indagar sobre a pretensão de validade da intencionalidade, pois qual a razão de questionar, se a proposta não seria levada em conta? Aparentar um processo de participação que não existe? Uma participação de fachada...

COL3, baseado no programa "Urna de cristal", mostra-se cético quanto ao avanço da e-participação no cenário do Estado colombiano. Sobre suas expectativas, o entrevistado pondera: "eu diria, da mesma forma, que não vejo em geral, uma grande tendência de participação por meios eletrônicos, não só com os partidos políticos, como nenhum dos outros órgãos de governo." Por outro lado, o depoente entende que surgem espaços para o engajamento cidadão quando os movimentos sociais se fazem presentes e cita o caso específico da participação das vítimas da guerrilha na elaboração da norma que trata desse tema específico.

Pelo conteúdo dos sites Gobierno Abierto e Urna de Cristal, evidencia-se um discurso claramente favorável à promoção da participação, incluída a e-participação, bem como todas as expressões de governo aberto em geral. Embora COL4 relativize esse posicionamento governamental favorável à participação, todos os demais depoentes entendem que além do discurso favorável, existe a real vontade política do governo na promoção das expressões de governo aberto em geral.

No plano dos recursos, a convergência dos depoimentos é no sentido de que são escassos. Sobre o assunto, COL2 remonta o problema do baixo de alcance do programa para as populações mais carentes e reclama da insuficiência de recursos para mudar essa realidade, enquanto COL4 pondera que falta ousadia para alocar os recursos e investimentos necessários, e COL1 destaca burocracia, excesso de regramentos e resistência do serviço público como barreiras para que se concretizem as iniciativas necessárias na área.

\section{Entrevistas no Chile}

No mês de maio de 2017 foram entrevistados cinco representantes de distintas ONGs chilenas, a saber: $\mathrm{CH} 1$, pessoalmente focado em dados abertos e membro de ONG voltada para o empoderamento; $\mathrm{CH} 2$, dirigente de entidade centrada em informação; $\mathrm{CH}$, integrante de organização que atua no campo da colaboração; CH4, membro de ONG direcionada para a informação; e CH5, dirigente de associação voltada para governo aberto.

No que diz respeito à conectividade, o Chile conta com bons índices em termos de América do Sul, embora haja segmentos da população que não contam com esse 
acesso ( $\mathrm{CH} 2$ ). $\mathrm{CH}$, por sua vez, acrescenta outro obstáculo para o indivíduo acessar a rede, o analfabetismo virtual, que impede o acesso das pessoas, pois elas "não sabem ir a um site". Indagada sobre a causa do problema, a depoente afirma que esse problema contribui para a manutenção do status quo, pois "não me interessa educar a ti, pois se eu te educo, vais intervir mais [...] vais poder fazer uma melhor contribuição".

Além do acesso, a amigabilidade mereceu reparos de vários entrevistados. $\mathrm{CH} 3$ lamenta que para navegar em determinadas páginas "é necessário um manual" e conclui que "os sites são difíceis de navegar." Numa análise comparativa, CH4 observa que cada site segue uma lógica própria e que a falta de regulamentos para a padronização das interfaces prejudica o uso das ferramentas disponíveis nos sites. CH1 acrescenta que, do seu ponto de vista, os portais estatais não são intuitivos.

No âmbito da pretensão de validade da compreensibilidade do conteúdo dos sites de e-participação e websites estatais em geral, a percepção dos depoentes não se mostrou muito positiva. $\mathrm{CH} 4$, por exemplo, afirmou que o cidadão "não é capaz de entender o que o Estado Ihe está entregando". Na mesma linha, CH2 debateu sobre as discussões técnicas nos portais e indaga "que importância tem isso para o processo democrático de participação para gerar qualidade?" Por final há o registro de falta de compreensão absoluta, qual seja, o caso das populações indígenas da tribo Mapuche, cuja língua é reconhecida pelo Estado. Apesar desse reconhecimento oficial, não há conteúdos na linguagem indígena, restando excluída de forma absoluta a população indígena que não fala o espanhol $(\mathrm{CH} 2)$. Verificase aqui, a exemplo da população pobre da Colômbia, o estabelecimento do que Habermas considera como a assimetria da comunicação, no caso concreto entre Estado e cidadão, em que medidas a favor do segmento carente da população são ignoradas em detrimento de investimentos em projetos voltados para grupos de maior poder político.

De acordo com a visão dos entrevistados, a e-participação encontra-se em um nível embrionário. Exemplo disso foram as módicas sete contribuições online para a elaboração do plano de governo aberto do Chile, para o período 2012 e 2013. Segundo $\mathrm{CH} 3$, o problema resulta de equívocos, como ignorar a cultura da sociedade, o tipo de consulta realizada e o seu processo de difusão. $\mathrm{CH} 4$ qualifica a e-participação no Chile como "quase nula", embora estranhe essa realidade face aos bons níveis de conectividade do país. De acordo com $\mathrm{CH} 5$, a tecnologia no Chile representa um tema que envolve as elites, não se vincula à participação ou prestação de contas e, portanto, não se conecta com "mudanças a partir da sociedade civil."

Em termos gerais, segundo $\mathrm{CH} 1$, há pouca participação cidadã no Chile em função do desinteresse da população, apesar de reconhecer nas expressões de participação 
existentes que atuam em diferentes esferas e com distintos impactos na sociedade algumas verdadeiras iniciativas de participação, sendo outras consideradas como participação de "maquiagem". Por final, o depoente conclui: "creio que no Chile estamos com a participação mais de maquiagem. Mais superficial." Sob os cânones da TAC, cabe indagar da legitimidade, da intencionalidade e até da verdade de se promover uma participação de "maquiagem".

Uma importante causa dessa pouca expressividade da participação cidadã no Chile, segundo $\mathrm{CH} 5$, decorreria de que o programa de participação esteja a cargo de setores do estado "que não tem forte respaldo da autoridade." Essa realidade mostra que os agentes públicos que atuam no processo precisam de autoridade e poder delegado pelo Estado para conduzir um processo participativo, sob pena de tornarse ilegítimo, falso e de fachada. CH3 explica a dificuldade da inclusão da participação na agenda oficial pela metáfora da "mosca na orelha", pois a participação, como a mosca, incomoda, só que por meio de perguntas, interpelações e questionamentos.

O Chile, como a Colômbia e o Uruguai, pela adesão à OGP e a obrigatória adoção de seu modelo, convidou organizações da sociedade civil para integrarem as Mesas Ciudadanas com o objetivo de elaborarem o plano de ação nacional de governo aberto (participação, transparência, prestação de contas, governança e uso da tecnologia em governo). Sobre esse processo, $\mathrm{CH} 2$ questiona a legitimidade dessa participação em função da representação - "que sociedade civil representariam?" - e da falta de compreensão do cidadão acerca dos temas abordados, eis que são técnicos, discutidos entre técnicos, restando totalmente apartada a cidadania, sem qualquer tentativa de tradução desse tecnicismo para uma linguagem inteligível para o cidadão comum. Como agravante, $\mathrm{CH} 5$ afirma que a população, diante dessa exclusão, não vislumbra espaço de participação, "não crê que vai ser escutada e, portanto, não acredita nas mudanças que a autoridade deve fazer."

Retornando às organizações da sociedade civil, $\mathrm{CH} 2$, que é dirigente de uma delas, refere que há entidades que vislumbram a participação nos colegiados, como as Mesas Ciudadanas, como "um espaço para conseguir recursos, para financiar projetos, mais que representar a sociedade civil." Acrescenta que nunca viu essas organizações prestarem contas à sociedade e que, embora muitos dirigentes de ONGs se intitulem como representantes da sociedade civil, "eu asseguro que se a gente for até a população de situação econômica baixa, não os conhecem."

Outra importante discussão envolve os planos de ação, que $\mathrm{CH} 2$ qualifica como ambíguos em função da imprecisão do conceito de OGP e de governo aberto. O entrevistado acrescenta que o modelo geral determinado pelo organismo internacional, até pela conformidade com o posicionamento de seus mentores, caracteriza-se como um pacote neoliberal. Nessa linha, $\mathrm{CH} 5$ questiona sua atuação 
nesses colegiados ao indagar de que vale comemorar que atingiram $48 \%$ dos compromissos, pois "o que significa isso para a cidadania?". Essa talvez seja a grande questão sobre a importância desses planos: o que as medidas propostas valem para a cidadania? A entrevistada adverte que o discurso, que é chave para a OGP, "não existe para a cidadania em geral, só existe para a elite."

Pelas declarações dos depoentes, verifica-se que o discurso do governo é amplamente favorável ao governo aberto e à participação cidadã. Como demonstração dessa realidade, $\mathrm{CH} 5$ repetiu o discurso da Presidente da República, que afirmou "que a participação cidadã deveria estar no centro de todas as políticas públicas no Chile." Sobre a vontade política, há depoentes críticos, como $\mathrm{CH} 2$ e CH5. Mais moderado, $\mathrm{CH} 4$, embora acreditando no processo, discute a vontade política do governo ao designar como seu representante um servidor médio, do nível tático e sem poder decisório nas reuniões. Sobre os recursos, todos são unânimes ao reclamar da situação. Indagado se a participação era prioridade no Chile, $\mathrm{CH} 4$ responde direto: "Não, não é prioridade".

\section{Comparando a e-participação nos três países}

A ideia central deste tópico consiste em comparar os programas de e-participação nos três países a partir do ponto de vista dos entrevistados, buscando realizar uma síntese de todas as contribuições coletadas ao longo do trabalho de campo realizado. Como nos tópicos anteriores, os fundamentos da TAC servem como balizadores para realizar e aprofundar a análise das contribuições recebidas.

\section{Acessibilidade, amigabilidade e compreensibilidade}

Em termos de acesso à rede, conectividade, pode-se inferir o que segue dos depoimentos:

\section{Quadro 4-Comparativo de conectividade}

\begin{tabular}{|c|c|c|}
\hline Uruguai & Colômbia & Chile \\
\hline $\begin{array}{l}\text { Cobertura integral da } \\
\text { internet }\end{array}$ & $\begin{array}{l}\text { Cobertura regular, } \\
\text { com extensas áreas de } \\
\text { exclusão, como vastas } \\
\text { áreas de selva amazônica }\end{array}$ & $\begin{array}{l}\text { Cobertura muito boa, com } \\
\text { poucas áreas de exclusão, } \\
\text { como em regiões mais } \\
\text { remotas, com população } \\
\text { com reduzido poder } \\
\text { econômico e de pressão }\end{array}$ \\
\hline
\end{tabular}


No que se refere à amigabilidade e à pretensão de validade da TAC da compreensibilidade, o Quadro a seguir explicita o que segue:

Quadro 5 - Comparativo da amigabilidade (facilidade de navegação) e compreensibilidade.

\begin{tabular}{|c|c|c|c|}
\hline Quesito & Uruguai & Chile & Colômbia \\
\hline $\begin{array}{l}\text { Facilidade } \\
\text { navegação }\end{array}$ & $\begin{array}{l}\text { Com problemas } \\
\text { Não intuitiva }\end{array}$ & $\begin{array}{l}\text { Com problemas } \\
\text { Não intuitiva }\end{array}$ & $\begin{array}{l}\text { Com problemas } \\
\text { Não intuitiva }\end{array}$ \\
\hline Compreensibilidade & Com problemas & Com problemas & Com problemas \\
\hline
\end{tabular}

No quesito facilidade de navegação, todos os depoentes apontaram problemas, afirmando que as interfaces dos sites não são, via de regra, intuitivas. No que se refere à compreensibilidade, os conteúdos dos programas de e-participação não estão ao alcance do cidadão comum. Cabe uma reflexão neste ponto: a conectividade, em termos objetivos, depende de investimentos de monta, o que nem sempre está disponível, mas projetar sites amigáveis à navegação do cidadão e postar conteúdos inteligíveis para as pessoas comuns demanda expertise e vontade de realização, esforços significativamente menores. Então por que não se vislumbra nesses países uma preocupação com a amigabilidade e a compreensibilidade? Na verdade, tratase de discutir se há vontade política de promover a participação ou manter uma participação de "maquiagem". Cabe, sob a égide das pretensões de validade da TAC, indagar o porquê dessa falta de atenção e qual a intencionalidade disso.

\section{Discurso, vontade política e recursos}

Os depoentes manifestaram-se sobre o tema como segue:

\section{Quadro 6-Comparativo discurso, vontade política e recursos}

\begin{tabular}{|l|l|l|l|}
\hline & Uruguai & Colômbia & Chile \\
\hline Discurso & Pró participação & Pró participação & Pró participação \\
\hline Vontade Política & Pró e contra & Pró participação & Pró e contra \\
\hline $\begin{array}{l}\text { Recursos } \\
\text { Fonte: elaboração própria. }\end{array}$ & Escassos & Escassos & Escassos \\
\hline
\end{tabular}

A questão que permanece diz respeito a esse déficit em termos de recursos, pois 
se há um discurso favorável e uma vontade política sincera, como muitos defendem, a participação não deveria ser encarada como prioridade e, em assim sendo, não deveriam ser aportados os recursos para sua implementação?

\section{E-participação e participação em geral}

Apesar das iniciativas, dos programas, da filiação à OGP, dos planos de ação para a promoção de governo aberto, a percepção dos depoentes, que são pessoas que se envolvem com os eventos e que estão inseridas no meio do governo aberto, é no sentido de que a e-participação é muito pouco expressiva, bem como a participação tradicional, com exceção do Uruguai no último quesito. Pode-se afirmar que essa percepção é fruto do consenso dos depoentes e retrata a situação dos três países.

\section{Institucionalização}

O Quadro a seguir explicita a legislação referente à participação cidadã:

\section{Quadro 7 - Comparativo das legislações nacionais}

\begin{tabular}{|l|c|l|l|}
\hline & Uruguai & Colômbia & Chile \\
\hline Lei de Participação & Não tem & $1757 / 2015$ & $20500 / 2011$ \\
\hline Ênfase & $-.--\cdot--$ & $\begin{array}{l}\text { Consultas } \\
\text { populares }\end{array}$ & $\begin{array}{l}\text { Organização da } \\
\text { participação nas } \\
\text { agências públicas }\end{array}$ \\
\hline
\end{tabular}

Fonte: elaboração própria.

No Uruguai, a discussão sobre a legitimidade das deliberações (pretensão da legitimidade) e a crítica recaem exatamente na ausência de normas que regulem a participação, principalmente nas "mesas de diálogo", procedimento de deliberação dos planos de ação do país junto à OGP.

\section{Programas de e-participação}

Apenas a Colômbia conta com um programa institucional ${ }^{4}$, a Urna de Cristal, multicanal, que trata de governo aberto, mas principalmente de participação, com destaque para a e-participação. Não houve por parte dos depoentes do Uruguai e do Chile qualquer menção a alguma iniciativa nesse sentido ou de previsão de criação de algo semelhante.

\footnotetext{
${ }^{4}$ Há outros programas setoriais, como, por exemplo, o Senador Virtual no Chile (http://www.senadorvirtual.cl/), mas Urna de Cristal é o único programa institucional, do Poder Executivo, envolvendo todo o governo.
} 
Colegiados para elaboração e monitoramento dos planos de ação de governo aberto.

\section{Quadro 8 - Comparativo dos processos de elaboração e monitoramento dos planos de ação OGP}

\begin{tabular}{|l|l|l|l|}
\hline Consultas & \multicolumn{1}{|c|}{ Uruguai } & \multicolumn{1}{|c|}{ Colombia } & \multicolumn{1}{|c|}{ Chile } \\
\hline Processo & $\begin{array}{l}\text { Consultas online com } \\
\text { ínfimos resultados }\end{array}$ & $\begin{array}{l}\text { Reuniões } \\
\text { descentralizadas via } \\
\text { internet }\end{array}$ & $\begin{array}{l}\text { Consultas online } \\
\text { com ínfimos } \\
\text { resultados }\end{array}$ \\
\hline & $\begin{array}{l}\text { Mesas de diálogo } \\
\text { (governo, sociedade } \\
\text { civil e academia) }\end{array}$ & $\begin{array}{l}\text { Reuniões do governo } \\
\text { com a sociedade civil, } \\
\text { academia }\end{array}$ & $\begin{array}{l}\text { Mesas de } \\
\text { negociação } \\
\text { (governo, } \\
\text { sociedade civil e } \\
\text { academia) }\end{array}$ \\
\hline Fonte: elaboração própria. & & \\
\hline
\end{tabular}

Fonte: elaboração própria.

Para a elaboração do plano de ação, a Colômbia promoveu uma discussão, por meio de uma ferramenta própria de tecnologia da informação, que possibilitou a inclusão de cerca de 300 pessoas para debater os temas de governo aberto, passando, no estágio seguinte, para a deliberação em um colegiado muito semelhante ao do Uruguai e Chile. Nesses dois países, houve uma fase prévia de e-participação, dirigida para receber contribuições online da população, com resultados muito pouco expressivos, passando, para as mesas de diálogo (Uruguai) ou cidadãs (Chile) a competência de elaborar, aprovar e monitorar os planos e medidas que orientam os rumos nacionais em termos de governo aberto.

Esses colegiados obedecem à determinação da OGP que estabelece que as organizações da sociedade civil devem participar da elaboração e monitoramento dos planos de ação de governo aberto. Sob o prisma da pretensão da legitimidade, surgem discussões sobre a quem compete representar a sociedade civil e se cabe ao Estado escolher as organizações que vão estabelecer aquilo que ele deve cumprir. Outra polêmica versa sobre a intencionalidade das entidades escolhidas para atuar nessas mesas e eventuais manobras para sua inclusão, visto que participar desses eventos resulta em prestígio, viagens, consultorias e facilidade para financiamentos de projetos. Por final, essas "mesas" constituem a forma que os países encontraram para cumprir com as determinações da OGP às nações aderentes, restando o debate sobre a legitimidade desse modelo, sua utilidade e o ganho real da sua adoção. 


\section{Estrutura de suporte à participação}

A participação, para ser considerada como ação social comunicativa, depende da conjugação de três elementos fundamentais, considerados nessa estrutura como seus pilares. O primeiro deles é o discurso, pois um discurso verdadeiro (pretensão de validade da verdade) somente se legitima (pretensão da legitimidade) se devidamente alinhado com a vontade política (segundo pilar), ou seja, se o discurso reflete uma vontade política concreta. Essa vontade política, por sua vez, somente se traduz em resultados efetivos pela intenção (pretensão da intencionalidade) real e manifesta de destinar recursos (terceiro pilar) para a participação. Em termos resumidos, somente um discurso e uma vontade política coerentes, traduzidos por uma alocação de recursos verdadeira pode suportar um sistema participativo, sob pena de estarmos diante de um processo enganoso e dissimulatório, ou seja, típico de uma ação estratégica. A Figura a seguir retrata a estrutura de suporte à participação com base na TAC.

\section{Figura 1 - Estrutura de suporte à participação}

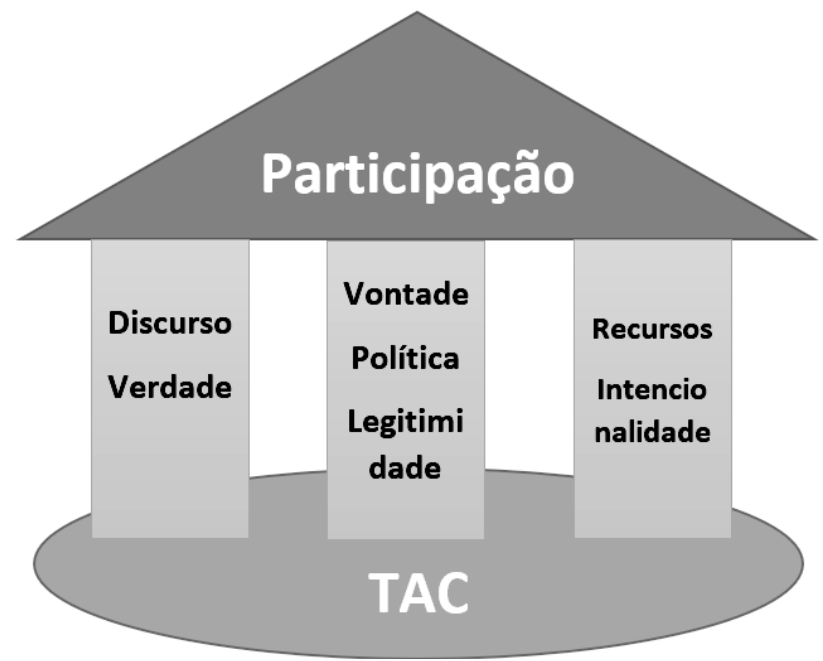

\section{Considerações finais}

Ultrapassadas a introdução, a breve abordagem da literatura e a metodologia, o presente estudo adentrou na análise das contribuições dos representantes das ONGs dos três países, de forma a estudar, entender e comparar os respectivos programas de participação. Por meio de uma análise crítica das contribuições, verificou-se que há um descolamento entre a versão oficial, consubstanciada pelo seu discurso, e a realidade, em termos de recursos aplicados na e-participação. A vontade política 
remanesceu num meio termo, aparentando, segundo os depoentes, ser favorável à e-participação, mas claudicante no que diz respeito à sua implementação.

No que refere à contribuição teórica, a primeira delas consiste em demonstrar a aplicabilidade da TAC no campo da administração da informação, interpretando a comunicação virtual à luz das pretensões de validade. No mesmo âmbito, o estudo apontou para a existência de dois requisitos adicionais para o estabelecimento da comunicação virtual, a conectividade e amigabilidade, que antecedem a compreensão dos conteúdos. Merece destaque, como contribuição teórica, a estrutura de suporte à participação com base na TAC e formada pelos três pilares: discurso, vontade política e recursos. Por final, a comparação dos três programas de participação constitui importante legado, apontando, embora as diferenças pontuais, forte semelhança entre eles, até porque seguem o mesmo modelo da OGP.

O conjunto de depoimentos apontaram para três questões que merecem maior reflexão:

- pouca expressividade da e-participação, quadro para o qual contribuíram a falta de amigabilidade das ferramentas, a difícil compreensão dos conteúdos e consultas cujo teor não dizem respeito ao cidadão (com exceção do Uruguai, a participação tradicional mostrou-se insatisfatória nos demais países);

- modelo da OGP que os países devem aderir (integrar à OGP representa adquirir um selo de "bom comportamento" como país democrático) e que deveria promover práticas de empoderamento, mas de discutíveis resultados efetivos no que se refere a benefícios efetivos para a cidadania; e

- generalizada falta de recursos dos programas (financeiros, expertise, recursos humanos, técnicos e poder para as autoridades públicas que atuam no ramo).

Às questões problemáticas apresentadas, este estudo sugere aos programas de participação a adoção do elenco de medidas práticas a seguir:

I. Definir estratégias e diretrizes que devem nortear o processo de e-participação, estabelecendo temas de consulta importantes e que "falem" para o cidadão.

II. Investir em campanhas publicitárias que elaborem a estratégia de divulgação e os textos das consultas com explicações compreensíveis ao cidadão.

III. Investir em expertise para que os programadores desenvolvam e atualizem, junto com o usuário, interfaces mais simples e de fácil navegação.

IV. Estruturar equipes treinadas para receber as demandas, responder prontamente as questões ou rotear, quando for o caso, mantendo um monitoramento constante de forma a garantir um pronto retorno ao usuário.

V. Empoderar os programas de participação e os seus gestores, dotando a eles de real poder de decisão. 
VI. Discutir a adesão ao modelo OGP a partir dos seguintes tópicos: contribuição real para o panorama nacional da participação e governo aberto em geral; a efetividade da forma de implantação; possibilidade de alterar a aplicação do modelo, adequando a uma realidade mais próxima; prejuízo nacional e internacional de uma eventual ruptura.

VII. 7. Adotar a estrutura de suporte à participação como norte do processo.

VIII. Importante registar, consoante se evidencia pela discussão neste artigo, mormente pelas inquietações apresentadas pelas pretensões da TAC, que a participação cidadã e o governo aberto, em última análise, não são intrinsicamente bons, benéficos, empoderadores etc., podendo tornar-se excludentes, opressores e dissimuladores, dependendo da legitimidade e intencionalidade de quem as executa e da verdade dos fins a que se pretende chegar.

Os representantes das organizações não governamentais que contribuíram para este estudo representam um contingente de pessoas que conhecem o processo de participação nos seus países, mas não constituem o único segmento. Há outros importantes stakeholders que podem contribuir sobremaneira para nova visão do cenário. A limitação deste estudo propicia, por outro lado, que futuros estudos incorporem outros segmentos sociais, como funcionários do governo, academia, representantes da imprensa, dentre outros. Da mesma forma, trabalhos futuros poderiam incorporar outros países do continente, de forma a propiciar o entendimento do fenômeno numa região marcada por diferenças econômicas, sociais e obviamente de poder. Por final, importante mencionar que a e-participação representa um caminho sem volta de gestão e governança públicas, cabendo aos governos estudarem e entenderem a questão de forma a explorar essa ferramenta em sua plenitude, cumprindo, assim, o seu papel junto ao jurisdicionado.

\section{Referências bibliográficas}

AgESIC. Sociedad de Gobierno Abierto. Informe Consulta Pública. Disponível em: https://www.agesic.gub.uy/innovaportal/file/3801/1/informe_consulta_publica. pdf. Acesso em 26 jan., 2017.

ARNSTEIN, Sherry R. A ladder of citizen participation. Journal of the American Institute of planners, v. 35, n. 4, p. 216-224, 1969.

ÅsTRÖM, Joachim et al. Understanding the rise of e-participation in non-democracies: domestic and international factors. Government Information Quarterly, v. 29, n. 2, p. 142-150, 2012.

ATTARD, Judie et al. A systematic review of open government data initiatives. Government Information Quarterly, v. 32, n. 4, p. 399-418, 2015.

Biblioteca del Congreso Nacional de Chile (BCN). Disponível em: <https://www. leychile.cl/Consulta/listaresultadosimple?cadena=20500>. Acesso em 30 jan., 2018. 
CAStells, Manuel. Comunicación y poder. Madrid: Alianza. 679 p., 2009.

CECEZ-KECMANOVIC, Dubravka. Basic assumptions of the critical research perspectives in information systems. HOWCROFT, Debra; TRAUTH, Eileen (Org.). Handbook of critical information systems theory and applications. Northhampton: Edward Elgar publishing, Inc. 2005, p. 19 a 46.

DAVIES, Tim G.; BAWA, Zainab Ashraf. The promises and perils of open government data (OGD). The Journal of Community Informatics, v. 8, n. 2, 2012.

DINI, Alfatika Aunuriella; WAHID, Fathul; Sæb $\varnothing, \varnothing$ ystein. Affordances and constraints of social media use in e participation: perspectives from Indonesian politicians. In: PACIS. 2016. p. 341.

DoOLIN, Bill; MACLEOD, Laurie. Towards critical interpretivism in IS research. Handbook of critical information systems theory and applications. Northhampton: Edward Elgar publishing, Inc. 2005, p. 244 a 271.

Evans, Angela M.; CAMPos, Adriana. Open government initiatives: challenges of citizen participation. Journal of Policy Analysis and Management, v. 32, n. 1, p. 172185, 2013.

Fairclough, N. Discurso, mudança e hegemonia. Pedro, E. R. (Org.). Análise Crítica do Discurso: uma perspectiva sociopolítica e funcional. Lisboa: Caminho, p. 77 a 104, 1998.

GiolA, Dennis A.; CoRley, Kevin G.; HAMILTON, Aimee L. Seeking qualitative rigor in inductive research: notes on the Gioia methodology. Organizational Research Methods, v. 16, n. 1, p. 15-31, 2013.

Gobierno En Línea. Que es Gobierno en Línea. Disponível em: <http://vive. gobiernoenlinea.gov.co/>. Acesso em 27 jan., 2018.

GRUEN, Nicholas Engage: Getting on with government. Report of the Government 2.0. The Taskforce, 2009.

HABERMAS, Jürgen. Teoria do agir comunicativo: racionalidade da ação $e$ racionalização social. Tradução de Paulo Astor Soethe e revisão técnica Flávio Beno Siebeneichler. WMF Martins Fontes. v.1, 704 p., 1981/2012.

JÜRGEN. Teoria do agir comunicativo: sobre a crítica da razão funcionalista. Tradução Flávio Beno Siebeneichler. São Paulo, WMF Martins Fontes, v. 2, 811 p., 1981/2012. HABERMAS, Jürgen. Teoría de la acción comunicativa: complementos y estudios previos. Tradução de Manuel Jiménez Redondo. Segunda edição Madri, Cátedra, p.507, 1984/1994.

HANSSON, Karin; BelKaCEM, Kheira; EKEnBERG, Love. Open government and democracy: a research review. Social Science Computer Review, v. 33, n. 5, p. 540555, 2015.

HARRISON, Teresa M. et al. Open government and e-government: democratic challenges from a public value perspective. Information Policy, v. 17, n. 2, p. 83-97, 2012.

HARRISON, Teresa M.; PARDO, Theresa A.; COOK, Meghan. Creating open government ecosystems: a research and development agenda. Future Internet, v. 4, n. 4, p. $900-$ 928, 2012. 
LEE, Gwanhoo; KWAK, Young Hoon. An open government maturity model for social media-based public engagement. Government information quarterly, v. 29, n. 4, p. 492-503, 2012.

MARX, Karl Heinrich; ENGELS, Friedrich. O Manifesto Comunista. Friedrich. Ed. Ridendo Castigat Mores, v. 1848, 1999. MEDAGLIA, Rony. E participation research: moving characterization forward (2006-2011). Government Information Quarterly, v. 29, n. 3, p. 346-360, 2012.

MeIJeR, Albert J.; CURTIN, Deirdre; HILlebrandT, Maarten. Open government: connecting vision and voice. International Review of Administrative Sciences, v. 78, n. 1, p. 10-29, 2012.

MERGEL, Ines. A framework for interpreting social media interactions in the public sector. Government Information Quarterly, v. 30, n. 4, p. 327-334, 2013.

MERGEL, Ines. Social media adoption and resulting tactics in the US federal government. Government Information Quarterly, v. 30, n. 2, p. 123-130, 2013.

MYERS, Michael D. et al. Qualitative research in information systems. Management Information Systems Quarterly, v. 21, n. 2, p. 241-242, 1997.

OliveIRA, Samuel Antonio Merbach de. Norberto Bobbio: teoria política e direitos humanos. Revista de Filosofia, v. 19, n. 25, 2007.

PANOPOUlOU, Eleni; TAMBOURIS, Efthimios; TARABANIS, Konstantinos. Success factors in designing e participation initiatives. Information and Organization, v. 24, n. 4, p. 195-213, 2014.

PEDRO, E. R. Análise crítica do discurso: aspectos teóricos, metodológicos e analíticos. In: Pedro, E. R. (Org.). Análise Crítica do Discurso: uma perspectiva sociopolítica e funcional (p. 19-46) Lisboa: caminho, 1998.

Picazo-Vela, Sergio; GutiérRez-Martínez, Isis; LunA-ReYes, Luis Felipe. Understanding risks, benefits, and strategic alternatives of social media applications in the public sector. Government information quarterly, v. 29, n. 4, p. 504-511, 2012.

RUIJER, Erna HJM et al. Breaking through barriers: the impact of organizational culture on open government reform. Transforming Government: People, Process and Policy, v. 10, n. 2, p. 335-350, 2016.

SANDOVAl-AlmAZAN, Rodrigo; GIL-Garcia, J. Ramon. Toward an integrative assessment of open government: Proposing conceptual lenses and practical components. Journal of Organizational Computing and Electronic Commerce, v. 26, n. 1-2, p. 170-192, 2016.

Sæb $\varnothing, \varnothing y s t e i n ;$ ROSE, Jeremy; FLAK, Leif Skiftenes. The shape of e participation: characterizing an emerging research area. Government information quarterly, v. 25, n. 3, p. 400-428, 2008.

SCHULZ, Daniel; NeWIG, Jens. Assessing online consultation in participatory governance: conceptual framework and a case study of a national sustainabilityrelated consultation platform in Germany. Environmental Policy and Governance, v. 25, n. 1, p. 55-69, 2015.

SPILIOTOPOULOU, Lefkothea et al. A framework for advanced social media exploitation 
in government for crowdsourcing. Transforming Government: People, Process and Policy, v. 8, n. 4, p. 545-568, 2014.

SUSHA, Iryna; GRÖNLUND, Åke. Context clues for the stall of the citizens' initiative: lessons for opening up e-participation development practice. Government Information Quarterly, v. 31, n. 3, p. 454-465, 2014.

TREASURY, H. M. Putting the frontline first: smarter government. Derecho Internacional. 2009.

VAN DJIK, J. A. G. M. Digital democracy: vision and reality. Public Administration in the Information Age, v. 19, n. 1, p. 49, 2012.

Veujović, Nataša; Bogdanović-Dinić, Sanja; StoIMENOV, Leonid. Benchmarking open government: an open data perspective. Government Information Quarterly, v. 31, n. 2, p. 278-290, 2014.

WAKABI, Wairagala; GröNLUND, Åke.Citizen-to-Citizenvs. Citizen-to-Government e participation in Uganda: implications for research and practice. In: International Conference on Electronic Participation. Springer, Cham, 2015, p. 95-107.

Zavattaro, Staci M.; Sementelli, Arthur J. A critical examination of social media adoption in government: introducing omnipresence. Government Information Quarterly, v. 31, n. 2, p. 257-264, 2014.

\section{Jorge Lheureux de Freitas}

Mestre e doutorando em Administração e Negócios pela Pontifícia Universidade Católica do Rio Grande do Sul (PUCRS) e visiting scholar no Center for Technology in Government, Universidade de Albany (EUA) e Tallin University of Technology, Tallin (Estônia). Contato: Iheureuxjlf@gmail.com

\section{Marie Anne Macadar}

Doutora em Administração pela Universidade de São Paulo (USP (2012). Visiting scholar na Cambridge University (Inglaterra) e no Center for Technology in Government (State University of New York, USA). Atualmente é professora associada da COPPEAD da Universidade Federal do Rio de Janeiro (UFRJ). Contato: marie.macadar@coppead.ufrj.br

\section{Eder Henriqson}

Doutor em Engenharia de Produção pela Universidade Federal do Rio Grande do Sul (UFRGS). Atualmente é Professor Titular e Decano da Escola de Negócios da Pontifícia Universidade Católica do Rio Grande do Sul (PUCRS). Contato: ehenriqson@pucrs.br. 